\title{
Nonlinear Dynamic Analysis of Direct Acting Tensioner of an Offshore Floating Platform
}

\author{
Zong-Yu Chang ${ }^{1, *}$, Xin Duan $^{1}$, Zhong-Qiang Zheng ${ }^{1}$, Lin Zhao ${ }^{1}$, Yu-Hu Yang ${ }^{2}$, Xian-Yi Zhou ${ }^{1}$, \\ Peng Zhu ${ }^{1}$, Jing-Wen $\mathrm{He}^{1}$ \\ ${ }^{1}$ College of Engineering, Ocean University of China, Qingdao, China \\ ${ }^{2}$ Laboratory of Mechanism Theory and Equipment Design of Ministry of Education, Tianjin University, Tianjin, China \\ Received 08 August 2019; received in revised form 25 December 2019; accepted 16 May 2020 \\ DOI: https://doi.org/10.46604/aiti.2020.4529
}

\begin{abstract}
The offshore floating platform is the key equipment in offshore and gas development. The significant heave motions occur with the excitation of wind and waves, which will affect the safety of a riser system. A direct acting tensioner can be applied to reduce the effects on the riser system and be widely used on different kinds of offshore platforms. Based on the analysis of the structure and working principle of a direct acting tensioner (DAT), the nonlinear dynamic performance of DAT riser system was studied. Additionally, the dynamic model of the DAT riser system is established and the dynamic response was gained by the numerical integration method. The differences of dynamic responses were compared between a linear model and a nonlinear model. The response on different side of the equilibrium position is asymmetric because of the nonlinear stiffness of DAT. The results can be helpful for the design of DAT.
\end{abstract}

Keywords: direct acting tensioner, nonlinear dynamic model, accumulator

\section{Introduction}

The explorations of oil and gas in the ocean have been rapidly developed in recent years [1]. Various offshore floating platforms are widely used in the deep sea oil and gas exploration [2]. The offshore floating platform undergoes significant heave motion with the excitation of waves, which may lead to a huge pulling force or a riser connecting to the seabed buckled. As a result, it brings about serious accidents. The riser tensioner can reduce the influence of the platform's heave motion on the riser by controlling the relative displacement of the offshore floating platform and the riser, which can ensure that the riser does not buckle due to compression, and does not damage abruptly due to excessive tension [3]. As shown in Fig. 1, the riser tensioner can be classified as a wireline riser tensioner system (WRT) and a direct acting tensioner system (DAT) [4]. The wireline riser tensioner system is revealed in Fig. 1(a). And the direct acting tensioner system is shown in Fig. 1(b). The wireline riser tensioner system needs frequent maintenance because the wireline easily worn. The direct acting tensioner system is directly connected to the riser and the platform, which has high reliability and long service life. Therefore, direct acting tensioners are welcomed by the industry [5].

Scholars have carried out related researches on the performance of riser tensioners. Xu [6] used a constant tension model to simulate the riser tensioner, and analyzed the deformation and movement of the riser by applying constant tension to the riser and ignoring the tension change caused by the platform heave motion. Yong [7] and Liu [8] applied a linear spring to

* Corresponding author. E-mail address: 854127780@qq.com 
simulate the tensioner. It is shown that the tensioner can reduce the influence of the heave motion on the riser to a certain extent. However, the nonlinear stiffness characteristics of the direct-acting tensioner cannot be reflected by the linear spring model.

The stiffness of the hydro-pneumatic tensioner will be changed with different stroke. Hatleskog [9] analyzed the nonlinear stiffness characteristics of the hydro-pneumatic tensioner and compared with results of the linear spring simulation. The results are indicated that the nonlinear characteristics of the tensioner can improve the compensation performance of the tensioner, thus the nonlinear characteristics of the tensioner cannot be ignored. Zhang [10] analyzed the parameters which will affect the compensation performance of the direct-acting riser tensioner. Researches demonstrated that the accumulator volume will influence the compensation performance.

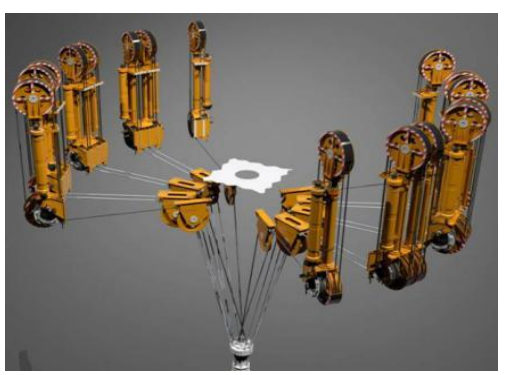

(a) wireline riser tensioner system

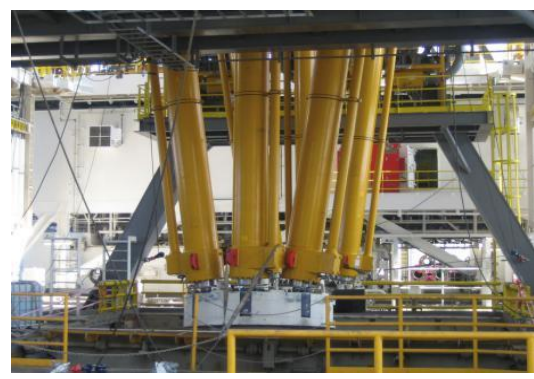

(b) direct acting tensioner system

Fig. 1 Wireline riser tensioner system and direct acting tensioner system

Hyewon Lee [11] considered the characteristics of hydro-pneumatic tensioners, and established a mechanical analysis model of the offshore floating platform-direct acting tensioner-riser system. Seung-Ho Ham [12] used a multibody dynamics system to analyze the movement of riser tensioners. Studies have shown that accumulator volume and wave amplitude are important parameters affecting the compensation performance of tensioners.

The previous analysis method ignored the effect of the tensioner on the riser tension change, applied directly to a constant tension on the top of the riser to simulate the tensioner to solve the dynamic response. In order to solve the above problems, in this study, the dynamic model of the marine riser system has been established. The nonlinear stiffness characteristics caused by the hydraulic and pneumatic system of the direct acting tensioner have been considered in the model. The dynamic response of the system has been solved based on numerical analysis methods. Furthermore, the influence of nonlinear stiffness on response has been analyzed.

\section{Structure and Principle of Direct Acting Tensioner}

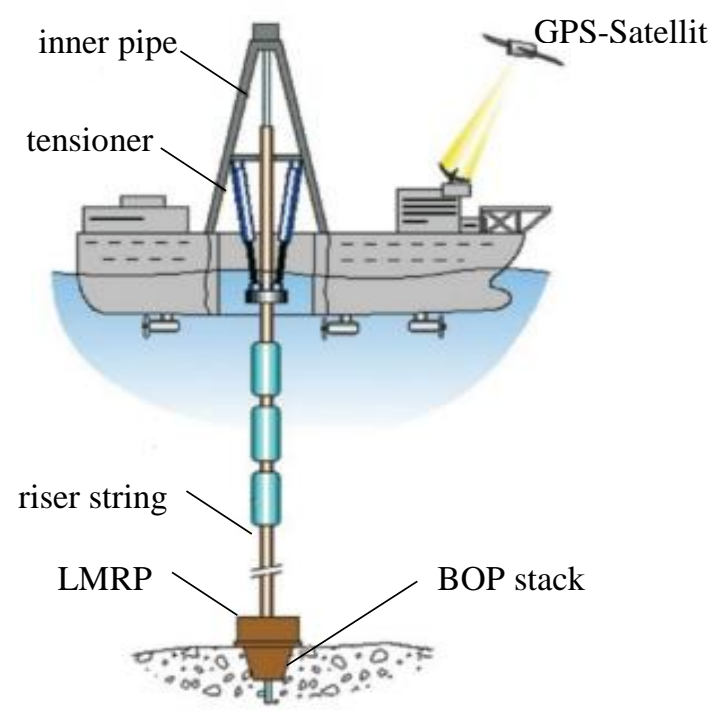

Fig. 2 The marine riser system 
The structure of the marine riser system is shown in Fig. 2. The upper end of the riser includes the inner pipe and outer pipe connected by a telescopic joint. The inner pipe and the floating platform are connected while the outer pipe has a lower flex joint connected to the lower marine riser package (LMRP) of the blowout preventer (BOP) stacked on its lower end.

The direct acting tensioner acts on the outer pipe of the riser through a tensioner ring, which is shown in Fig. 3.

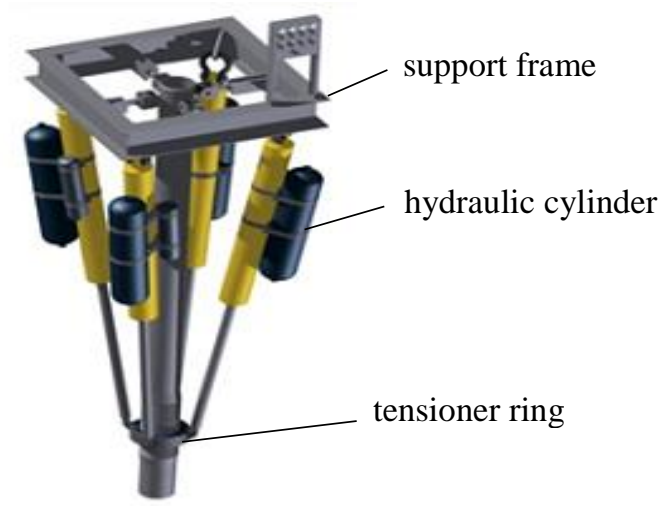

Fig. 3 Direct acting tensioner system

The direct acting tensioner is mainly composed of three parts: support frame, hydraulic cylinder, and tensioner ring. The support frame of the tensioner is installed on the platform. The accumulator provides power to compensate for the riser heave motion through the expansion and contraction of the hydraulic cylinder.

\section{Dynamic Analysis of the Marine Riser System}

\subsection{The analysis of tensioner performance}

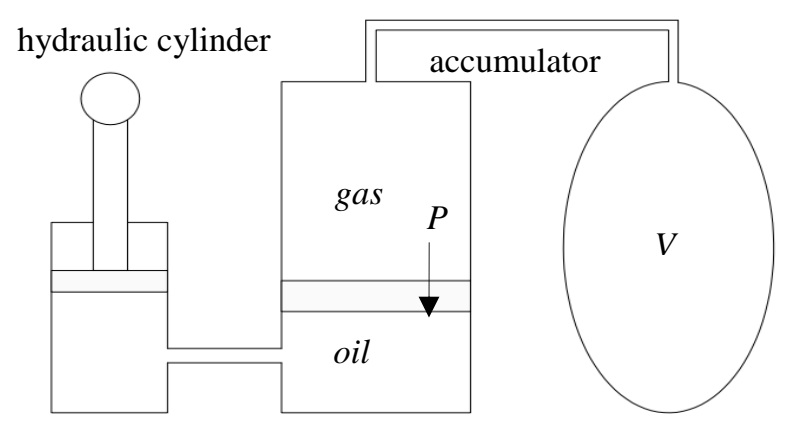

Fig. 4 The structure of direct acting tensioner system

Table 1. The parameters of hydraulic cylinder

\begin{tabular}{|c|c|c|c|}
\hline Component & Specifications & Value & Unit \\
\hline accumulator & volume & 3.2 & $\mathrm{~m}^{3}$ \\
\hline & Initial pressure & 190.2 & $\mathrm{Bar}$ \\
\hline hydraulic cylinder & Piston diameter & 470 & $\mathrm{Mm}$ \\
\hline & Piston rod diameter & 400 & $\mathrm{Mm}$ \\
\hline & Piston mass & 2510 & $\mathrm{Kg}$ \\
\hline
\end{tabular}

The structure of the hydraulic cylinder is shown in Fig. 4 and the parameters of the hydraulic cylinder are shown in Table 1. The rodless chamber is connected to the accumulator. The gas change process satisfies the conditions of the adiabatic process; therefore, it is suitable for the equation of state for the ideal gas. $V$ is the volume of the accumulator gas. $P$ is the gas pressure of the accumulator. $V_{0}$ is the initial volume of the gas, and $P_{0}$ is the initial pressure of the gas. According to the equation of state for the ideal gas, the four variables satisfy the equations as: 


$$
P_{0} V_{0}^{k}=P V^{k}
$$

The pressure $P$ is:

$$
P=P_{0}\left(\frac{V_{0}}{V}\right)^{k}=P_{0}\left(\frac{V_{0}}{V_{0}+A_{p} x}\right)^{k}
$$

where $A p$ is the piston diameter; $X$ is the displacement of the piston and the hydraulic cylinder force $F_{i}$ is:

$$
\begin{aligned}
& F_{i}=A_{p} p=A_{p} P_{0}\left(\frac{V_{0}}{V_{0}+A_{p} X}\right)^{k} \\
& F=\sum_{i=1}^{4} F_{i}
\end{aligned}
$$

where $F$ is the tensioner force. The relationship between tensioner force and the displacement of the piston is shown in Fig. 5 .

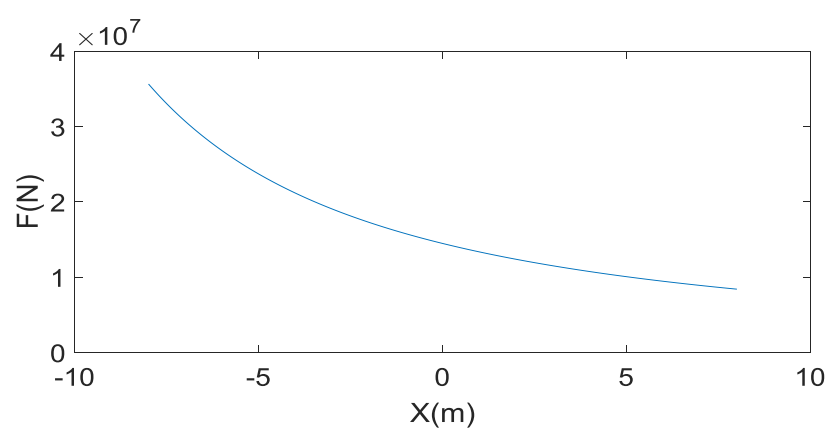

Fig. 5 The relationship between force and displacement of hydraulic cylinder

It is obvious that the relationship between force and displacement is nonlinear. In addition, the magnitude of stiffness is transforming with the change of the displacement.

$$
k_{1}=\frac{\Delta F}{\Delta l}=\frac{A_{p} \times P_{0}}{X}\left\{\left(\frac{1}{1+A_{p} X / V_{0}}\right)^{1.4}-1\right\}
$$

The stiffness curve is shown in Fig. 6.

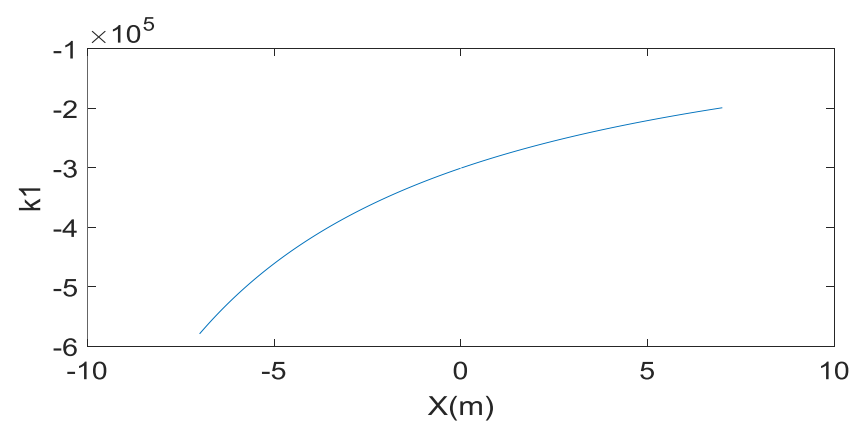

Fig. 6 The relationship between stiffness and displacement of riser-direct acting tensioner system

\subsection{Dynamics modeling of the riser system}

The model of direct acting riser tensioner with the floating platform and riser system is shown in Fig. 2. The tensioner applies tension to the riser through the tensioner ring to suppress the heave motion of the riser. The scheme of the dynamic model is indicated in Fig. 7. 

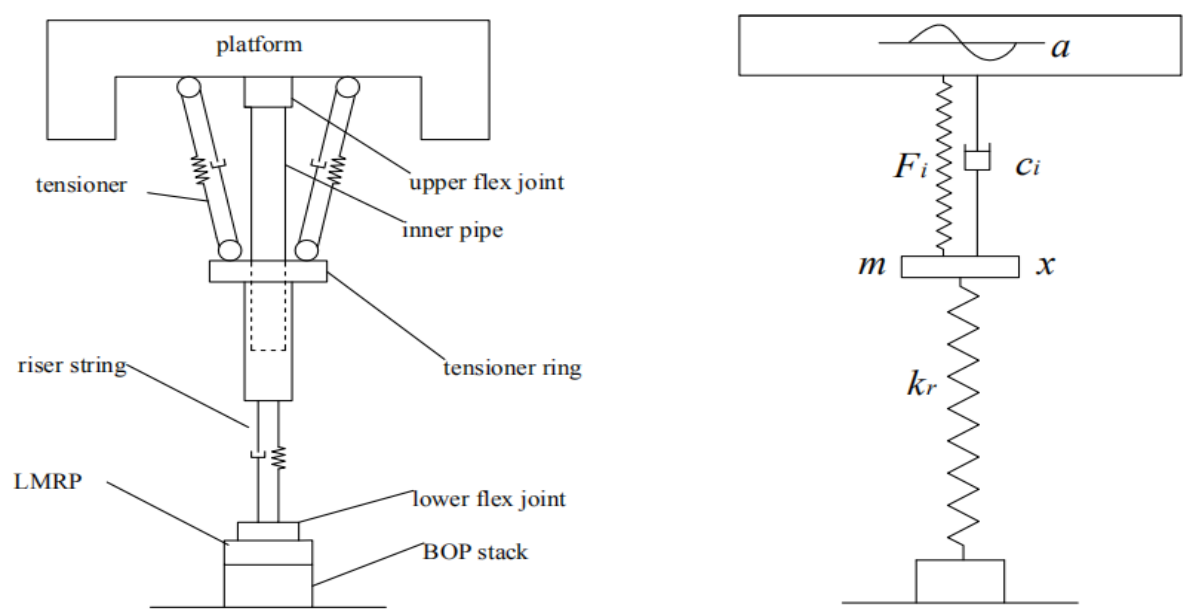

Fig. 7 Dynamics model of the marine riser system

Generally, the tilt angle for the hydraulic cylinders of the direct-acting tensioner is small. The effect on the tilt angle of the hydraulic cylinders on the lateral direction can be neglected. Under the excitation of the wave, the heave motion of platform can be assumed simple harmonic as $a$. Based on Eq. (3), the tension of the tensioner $F$ against the riser can be calculated and the motion of system can be written as:

$$
\begin{aligned}
& m \ddot{x}=\sum_{i=1}^{4} F_{i}-m g-\sum_{i=1}^{4} c_{i}(\dot{x}-\dot{a})-k_{r} x \\
& X=x-a \\
& F_{r}=k_{r} x
\end{aligned}
$$

where $m$ and $k_{r}$ respectively represent the riser mass and stiffness. $x$ and $F_{r}$ are the heave motion and tension of the riser respectively. $i$ and $c_{\mathrm{i}}$ represent the number of hydraulic cylinders and the hydraulic cylinder damping coefficient, respectively. The parameters of riser tensioner-riser system are shown in Table 2.

Table 2. The parameters of riser tensioner - riser system

\begin{tabular}{|c|c|c|}
\hline Specifications & Value & Unit \\
\hline Riser mass & $7.49 \times 10^{5}$ & $\mathrm{~kg}$ \\
\hline Number of hydraulic cylinders & 4 & \\
\hline Riser stiffness & 3430 & $\mathrm{kN} / \mathrm{m}$ \\
\hline Hydraulic cylinder damping coefficient & 967 & $\mathrm{~N} /(\mathrm{m} / \mathrm{s})$ \\
\hline
\end{tabular}

\section{Dynamic Response Analysis of the Marine Riser System}

\subsection{Dynamic response analysis of the riser}

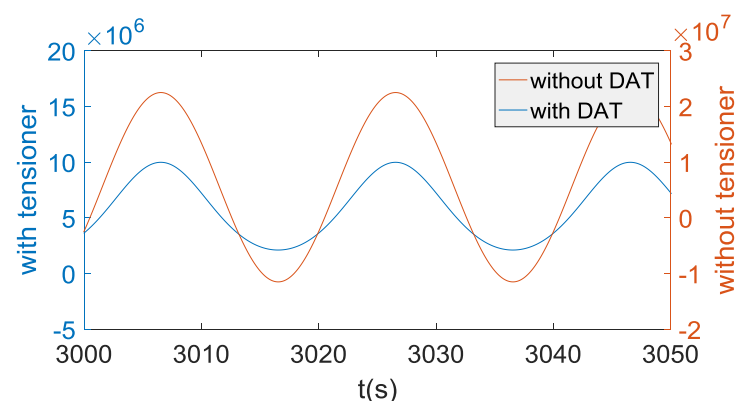

(a) The tension of the riser in presence or absence of the tensioner

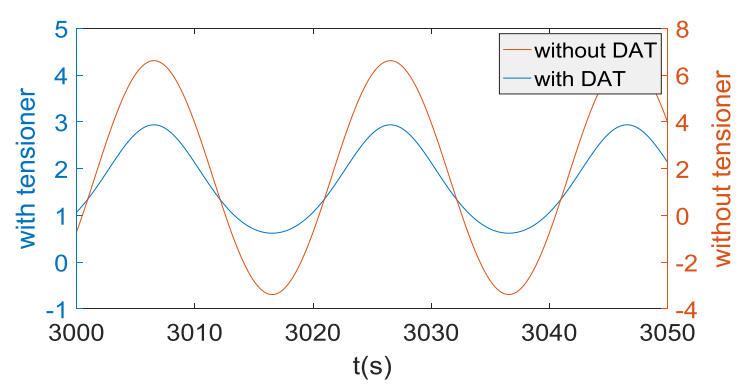

(b) The heave motion of the riser in presence or absence of a tensioner

Fig. 8 Riser response comparison with or without compensation 
The results of this part are obtained under the heave motion of the platform where the motion height $(\mathrm{H})=5 \mathrm{~m}$, and the period $(\mathrm{T})=20 \mathrm{~s}$ [13]. The response of the riser is shown in Fig. 8. Fig. 8(a) shows the tension response of the riser with or without rise tensioner. Fig. 8(b) reveals the heave motion of the riser with or without tensioner. According to the figure, it can be seen that with the riser tensioner, the oscillation magnitude of tension and heave motion is reduced obviously about $30 \%$ and $50 \%$.

\subsection{Analysis of nonlinear characteristics of riser tensioner}

In order to simplify the analysis, the nonlinear model of the riser tensioner can be equivalently linearized. When the displacement range of the piston is from $-8 \mathrm{~m}$ to $8 \mathrm{~m}$, the linear fitting curve is obtained as Fig. 9. The difference between linear and nonlinear model can be seen in this figure.

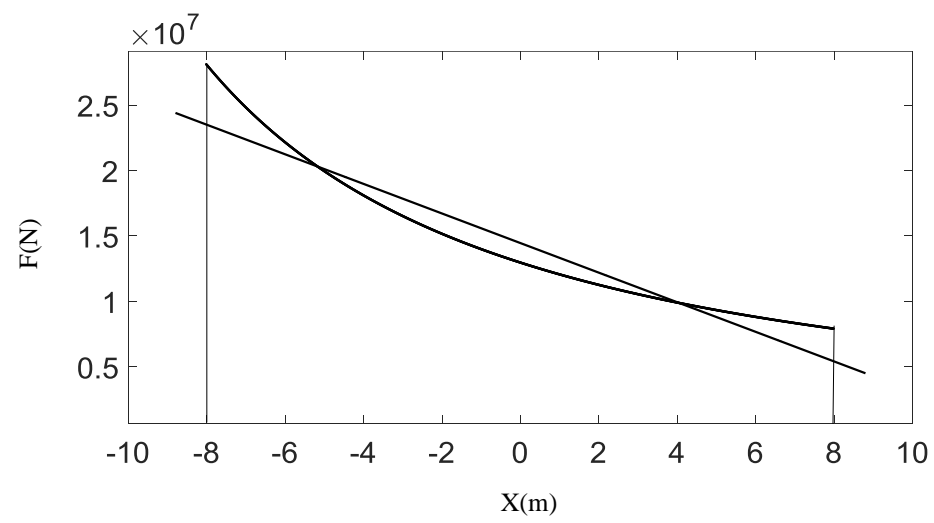

Fig. 9 Linear fit of hydraulic cylinder

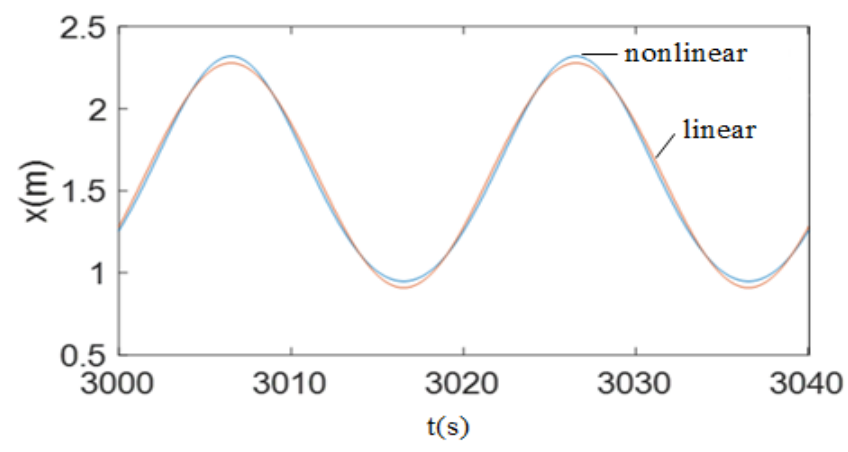

(a) Heave motion of riser with 3 meter displacement excitation

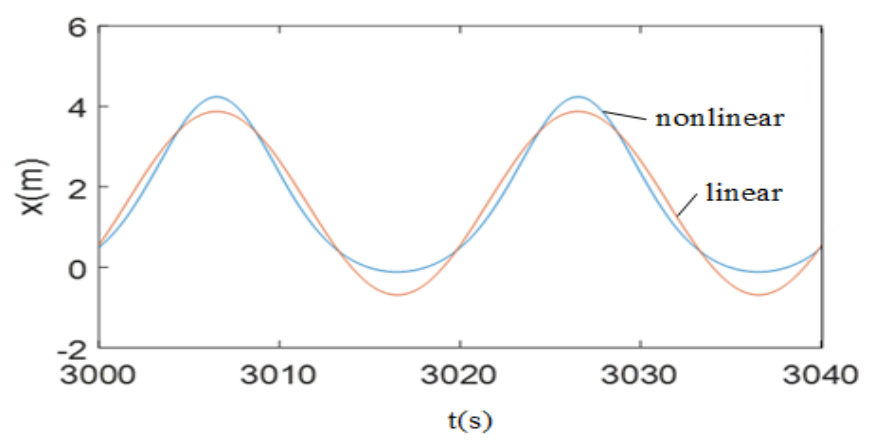

(c) Heave motion of riser with 10 meter displacement excitation

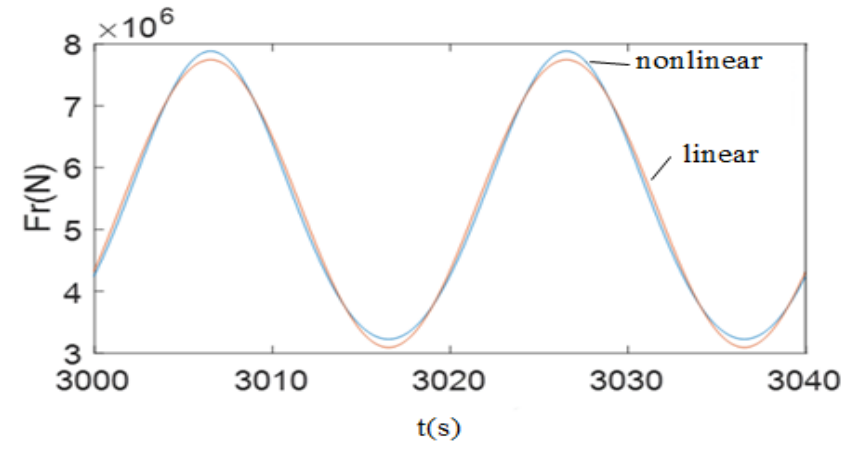

(b) Tension of riser with 3 meter displacement excitation

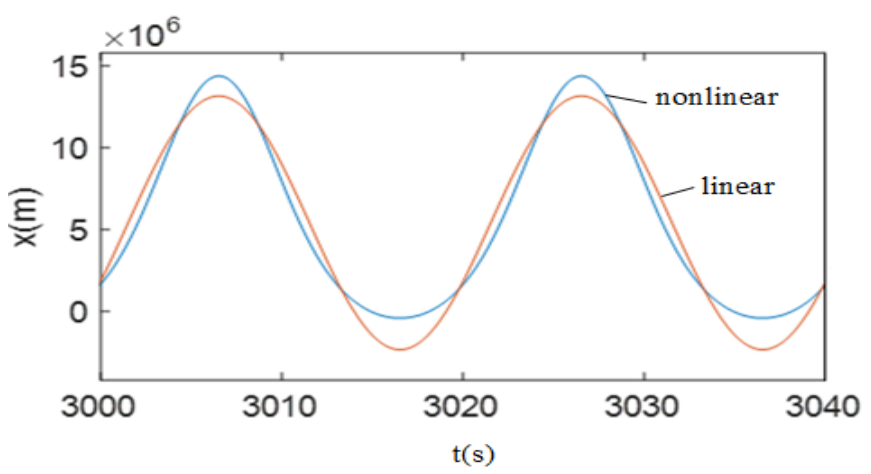

(d) Tension of riser with 10 meter displacement excitation

Fig. 10 Riser response

Based on the two models, the responses of tension force and heave motion of riser are shown in Figs. 10-11 with heave motion amplitude $3 \mathrm{~m}$ and $10 \mathrm{~m}$ of the platform. Fig. 10(a) and 10(b) are the heave motion and tension of the riser with 3 meter displacement excitation. Fig. 10(c) and (d) are the heave motion and tension of the riser with 10 meter displacement excitation. 
From Fig. 10(a) and 10(b), under the small amplitude motion of the platform, the results of the linear model and the nonlinear model agree extremely well. It is suggested that under small amplitude excitation, the linear model can be used instead of the nonlinear model However, when the platform motion reaches large amplitude, there are significant differences between the results of nonlinear model and linear model. It is obvious that the tension curve and motion curve is no longer symmetric in positive and negative directions for the nonlinear model.

The responses of the marine riser system with four different amplitudes heave motion of the platform are calculated as Figs. 11-12. Fig. 11 presents the vertical displacement of the riser and Fig. 12 indicates the tension of the riser. As shown in Figs. 11-12, the degree of symmetric is increased with the amplitude of the platform motion and the nonlinearity of hydraulic cylinder.

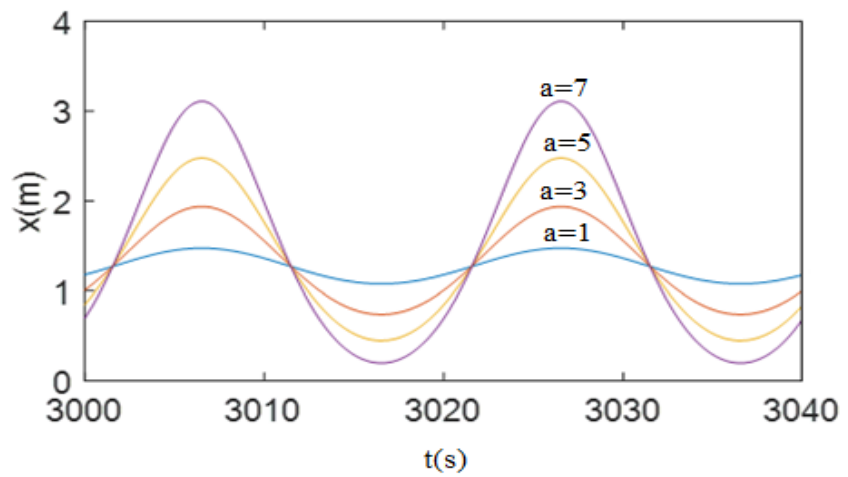

Fig. 11 The vertical displacement of riser

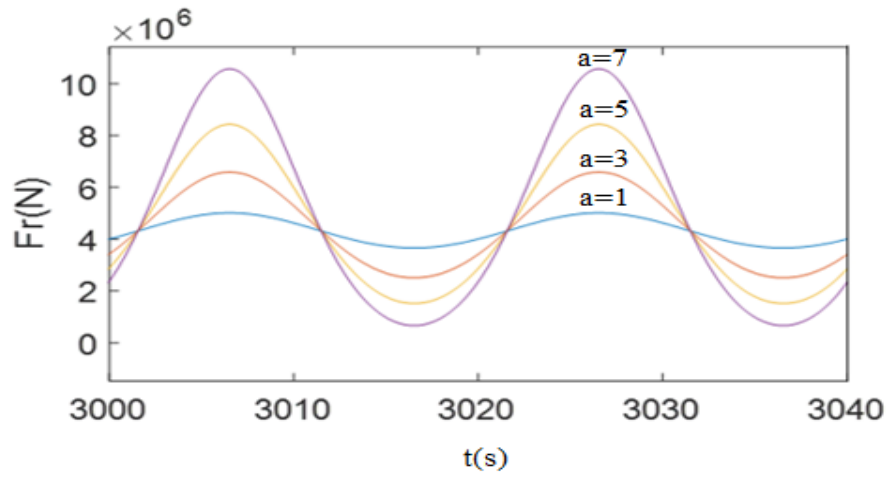

Fig. 12 The tension of riser

An index of asymmetric is carried out to represent the degree of asymmetric. What is more, the equilibrium position is assumed to be the steady state when the platform is not moving. The index $S$ is defined as the ratio between the positive displacement and the negative displacement of the riser as:

$$
S=\frac{x_{p}}{x_{n}}
$$

where $x_{p}$ is the positive displacement the riser, $x_{n}$ is the negative displacement. The index of asymmetry degree with the different exciting displacement of platform is shown in Fig. 13. The comparison of positive displacement and negative displacement is shown in Fig. 13. The index of asymmetry degree with the different exciting displacement of platform is shown in Fig. 14.

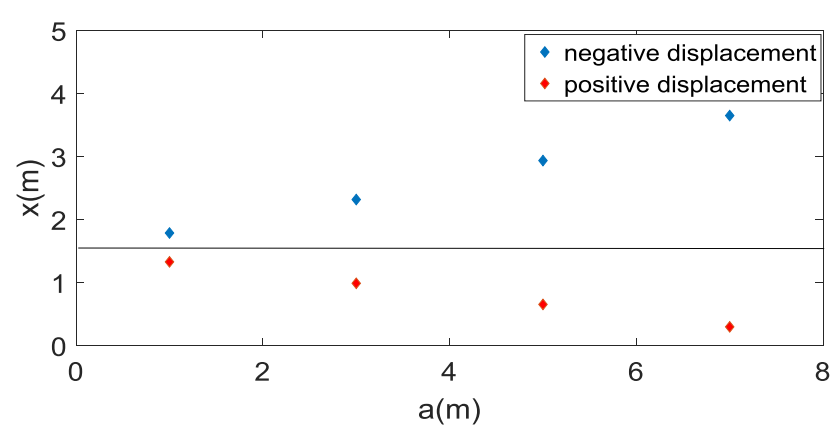

Fig. 13 Comparison of positive displacement and negative displacement

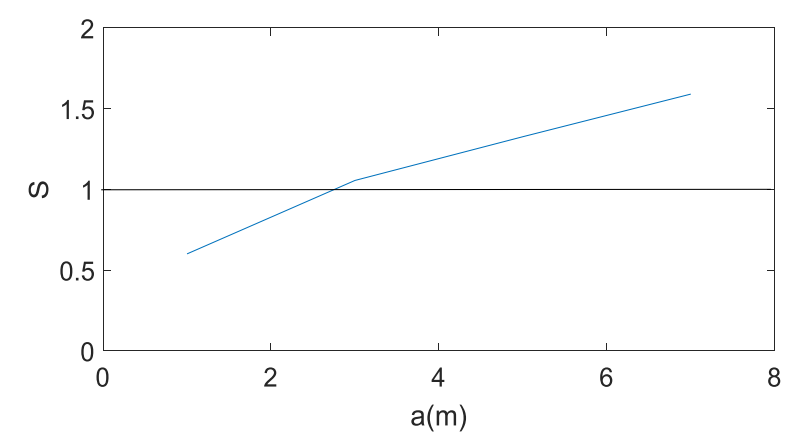

Fig. 14 Asymmetry index with different heave excitation

As referred in section 3, the stiffness of the riser tensioner decreases with the increase of the displacement of the riser. The stiffness in a negative direction is larger than the one in a positive direction. Therefore, the tensioner has a small displacement and large tension force in the negative direction. It would be beneficial for avoiding the buckling of the rise and keeping fairly tension force on the riser ring. 


\section{Conclusion}

In this study, the dynamic simulation of the marine riser system is carried out, and the dynamic response of the marine riser system is analysed. Dynamic model is established including the floating platform, rise tensioner and riser ring. The simplified model of DAT with pneumatic system is developed and the nonlinear stiffness of the riser tensioner is considered. Through the numerical simulation, the vertical motion of the marine riser system and the tension of the riser with different wave conditions are analysed. In low-amplitude wave conditions, the system response of the model considering nonlinear stiffness of DAT is similar to the result of the linear model; in high -amplitude wave conditions, the significant difference exists between the linear model and the nonlinear model. The asymmetrical response can be seen obviously in the nonlinear model. An index to represent the degree of asymmetry is carried out. The calculation suggests that with the increase in the heave motion amplitude of offshore, the asymmetrical degree will increase. The nonlinear characteristic of direct acting tensioner could be useful to prevent the buckling of the riser. In order to further improve the compensation performance of the riser tensioner, the impact of the riser hysteresis effect on the riser response should be analysed next. At the same time, most of the researches on the nonlinear stiffness characteristics of the riser tensioner are still in the theoretical research simulation stage. A test device should be established in the future to verify the effect of the tensioner nonlinear stiffness on its compensation performance in the experiment.

\section{Conflicts of Interest}

The authors declare no conflict of interest.

\section{References}

[1] T. Wang and Y. Liu, "Dynamic response of platform-riser coupling system with hydro-pneumatic tensioner," Ocean Engineering, vol. 166, pp. 172-181, October 2018.

[2] B. Chen, J. Yu, Y. Yu, L. Xu, H. Wu, and Z. Li, "Modeling approach of hydro-pneumatic tensioner for top tensioned riser," Journal of Offshore Mechanics and Arctic Engineering, vol. 140, no. 5, October 2018.

[3] R. G. Pestana, F. E. Roveri, R. Franciss, and, G. B. Ellwanger, "Marine riser emergency disconnection analysis using scalar elements for tensioner modeling," Applied Ocean Research, vol. 59, pp. 83-92, September 2016.

[4] J. K. Woodacre, R. J. Bauer, and R. A. Irani, "A review of vertical motion heave compensation systems," Ocean Engineering, vol. 104, pp. 140-154, August 2015.

[5] Y. Wu, "A new operability and predictability enhanced riser control system for deepwater marine operation: an integrated riser hybrid tensioning system,” Ph.D. dissertation, Dept. Elect. Eng., The University of Texas at Austin, 2015.

[6] Z. Q. Xu, W. Y. Tang, H. X. Xue, and Z. Q. Hu, "Safety assessment of a top-tensioned TLP production riser in disastrous marine environment," China Ocean Engineering, vol. 28, no. 3, pp. 44-49, 2010.

[7] Y. Peng and B. Zhao, "Analysis of factors influencing the crane heave compensation system compensation effect at deepwater drilling rig," Journal of Residuals Science \& Technology, vol. 13, no. 8, 2016.

[8] S. Liu and L. Li, "Control performance simulation on heave compensation system of deep-sea mining based on dynamic vibration absorber," International Conference on Digital Manufacturing \& Automation, December 2010, pp.441-445.

[9] J. T. Hatleskog and M. W. Dunnigan, "Heave compensation simulation for non-contact operations in deep water," Oceans, September 2006, pp. 1-6.

[10] Y. T. Zhang, Z. D. Liu, H. Jiang, G. B. Wu, and Z. L. Zhang, "Study on active force of compensation system for floating drilling platform,” Oil Field Equipment, vol. 39, no.4, pp. 1-4, April 2010.

[11] H. Lee, M. I. Roh, S. H. Ham, and S. Ha, "Dynamic simulation of the wireline riser tensioner system for a mobile offshore drilling unit based on multibody system dynamics," Ocean Engineering, vol. 106, pp. 485-495, September 2015.

[12] S. H. Ham, M. I. Roh, and J. W. Hong, "Dynamic effect of a flexible riser in a fully connected semisubmersible drilling rig using the absolute nodal coordinate formulation," Journal of Offshore Mechanics and Arctic Engineering, vol.139, no. 5, October 2017.

[13] W. Shisheng, X. Bin, and L. Xinzhong, "The motion response analysis of deep water typical TLP in environment conditions of south china sea," Shipbuilding of China, vol. 52, no. 1, pp. 94-101, 2011.

Copyright $\odot$ by the authors. Licensee TAETI, Taiwan. This article is an open access article distributed under the terms and conditions of the Creative Commons Attribution (CC BY-NC) license (https://creativecommons.org/licenses/by-nc/4.0/). 